\title{
Prevalence and Risk Factors Associated with Post Operative Infections in the Limbe Regional Hospital of Cameroon
}

\author{
Ngowe Ngowe $\mathrm{M}^{1, *}$, Toure $\mathrm{A}^{2}$, Mouafo Tambo $\mathrm{FF}^{1}$, Chichom $\mathrm{A}^{3}$, Tchounzou $\mathrm{R}^{3}$, Ako-Egbe $\mathrm{L}^{3}$ and \\ Sosso MA ${ }^{1}$
}

\author{
${ }^{1}$ University of Yaounde I, Cameroon \\ ${ }^{2}$ University of Conakry, Guinea \\ ${ }^{3}$ University of Buea, Cameroon
}

\begin{abstract}
Background: Postoperative infections (POIs) contribute to morbidity and mortality of surgical patients. There was no data on the prevalence and associated risk factors of POIs in the Limbe Regional Hospital (RLH).

Methods: Selected patients were those who underwent a surgical procedure and were admitted into the surgical or maternity ward of the LRH between January 2009 and August 2012. Data studied included demographic variables, type of surgical procedure performed and postoperative follow-up. Data was analyzed for evidence of POIs using the Chi-square test for categorical variables and test for significance of association between POI and sex, age, procedures performed, hospitalization ward and duration of hospital stay.

Results: 848 patients were selected among whom $78.8 \%$ were females. $62.1 \%$ of the patients were selected from the Obstetric and Gynaecology ward, while $37.9 \%$ were from the surgical ward. The mean age of the study subjects was $32.3 \pm 12.4$ years. 175 patients met the criteria for POI giving a prevalence of $20.6 \%$. The Obstetrics and Gynaecology ward had the highest prevalence of POI (61.7\%). Prevalence of POIs was highest (64.3\%) among patients in the $0-10$ years age group. Males (26.7\%) were at a higher risk of developing POIs .There was a statistically significant difference between POI and participants' age group $(\mathrm{p}<0.05)$. Peritonitis displayed the highest rate of POI $(36.6 \%)$ while tubal ligation had the lowest $(0 \%)$. Purulent wound discharge was the most frequent diagnostic criteria for postoperative infection.
\end{abstract}

Conclusion: The prevalence of POIs ranged from $0-36.6 \%$. Male sex and patients' age seemed to be associated with a higher risk of POIs. Surgery for acute generalized peritonitis had the highest risk of developing POIs.

Keywords: Infection, Surgery, Postoperative period, Ward, Peritonitis.

\section{INTRODUCTION}

Surgery is an essential component in health care. Complications after surgery account significantly for morbidity and mortality among patients after surgery. These complications in Sub-Saharan African settings are mainly anesthesia and infection-related [1]. It has been observed that poor surgical safety practices and systematization (e.g. prophylactic antibiotic therapy, confirmation of effective sterilization of instruments) are consistent with the burden of infections after surgery in our settings [1]. There is no data on the prevalence of postoperative infections in health facilities in the LRH. Our study aimed to determine the prevalence and risk factors related postoperative infections in the LRH.

*Address correspondence to this author at the University of Yaounde I, Cameroon; Tel: 0023799930972 / 77216858 ;

E-mail: nkouki2002@ yahoo.fr

\section{MATERIALS AND METHODS}

The design was a hospital-based retrospective descriptive study. The study was conducted in the Limbe Regional hospital within the Limbe Health District in the South West Region of Cameroon. Limbe is a coastal town far from the mains cities Yaounde and Douala in a small urban setting with limited quality medical resources. It is the main referral hospital in the region and has about 200 beds. The study was carried out from January 2009 to August 2012 . It consisted of a review of patient hospital records. All patients who underwent surgery and were admitted into the surgical or maternity ward of the LRH during the study period were included in the study. We chose these two wards because most patients were operated by the same general surgeon but were hospitalized in two different wards. The difference between the two wards is that one is exclusively female (maternity ward) and the other mixed.

Variables studied included sex and age of participants, hospitalization ward and type of surgical intervention and nature of the surgery (Altemeir classification), postoperative 
Table 1. Annual Variation of Prevalence of Surgical Procedures and Indications

\begin{tabular}{|c|c|c|c|c|}
\hline Procedure/ Indication & Year of $2009 n(\%)$ & Surgical $2010 n(\%)$ & Operation $2011 n(\%)$ & ToT. $n(\%)$ \\
\hline \multicolumn{5}{|l|}{ LAPAROTOMY } \\
\hline -Peritonitis & $12(7.6)$ & $11(7.0)$ & $11(7.0)$ & \\
\hline -Bowel obstruction & $6(3.8)$ & $3(1.9)$ & $5(3.2)$ & \\
\hline -Intussusception & $1(0.6)$ & $0(0.0)$ & $0(0.0)$ & \\
\hline -Bowel perforation & $5(3.2)$ & $7(4.5)$ & $6(3.8)$ & \\
\hline -A. Cholecystitis & $1(0.6)$ & $0(0.0)$ & $0(0.0)$ & \\
\hline -Pyloric perforation & $2(1.3)$ & $3(1.9)$ & $0(0.0)$ & 157 \\
\hline -Gastric outlet obst. & $0(0.0)$ & $1(0.6)$ & $1(0.6)$ & $(\mathbf{1 0 0})$ \\
\hline -Volvolus & $0(0.0)$ & $1(0.6)$ & $1(0.6)$ & \\
\hline -Duodenal perforation & $0(0.0)$ & $1(0.6)$ & $5(3.2)$ & \\
\hline -Pelvic abscess & $3(1.9)$ & $6(3.8)$ & $8(5.1)$ & \\
\hline -Ruptured ectopic pregnancy & $9(5.7)$ & $10(6.4)$ & $14(8.9)$ & \\
\hline -Others & $6(3.8)$ & $9(5.7)$ & $9(5.7)$ & \\
\hline \multicolumn{5}{|l|}{ HERNIA REPAIR } \\
\hline -L. inguinal hernia & $3(2.0)$ & $10(6.6)$ & $11(7.2)$ & \\
\hline -Umbilical hernia & $14(9.2)$ & $3(2.0)$ & $3(2.0)$ & \\
\hline -Bil. Inguinal hernia & $9(5.9)$ & $10(6.6)$ & $8(5.3)$ & \\
\hline -Epigastric hernia & $3(2.0)$ & $10(6.6)$ & $0(0.0)$ & 152 \\
\hline -Femoral hernia & $3(2.0)$ & $7(4.6)$ & $8(5.3)$ & $(\mathbf{1 0 0})$ \\
\hline -R. inguinal hernia & $13(8.6)$ & $10(6.6)$ & $15(9.9)$ & \\
\hline -Incisional hernia & $6(3.9)$ & $5(3.3)$ & $1(0.7)$ & \\
\hline
\end{tabular}

outcome (infection, dead and no infection). No records of the duration of surgery, antibiotic prophylaxis and causative agents of POIs were mentioned in the files. These are important determinants of POIs. Surgical asepsis was not assessed in our study.

Diagnostic criteriafor probable postoperative infection were body temperatures greater than $38^{\circ} \mathrm{C}$ after the first 48 hours following surgery and during the period of hospitalization. The persistence of such temperature for two consecutive days, despite anti-malaria treatment, was considered diagnostic of postoperative infection. Purulent surgical site discharges, wound dehiscence and offensive odors from the surgical wound were also considered diagnostic of SSI. Full blood count findings (e.g. leucocytosis) recorded in the patient's postoperative notes was also diagnostic. The presence of at least two of the above criteria was considered diagnostic of POIs in the study. Statistical analysis was conducted using Epi Info version 3.5.1. Ratios and proportions were compared using Pearson's Chi-Square test. Means were compared using the Student t-Test. Results were presented in tables, histograms and graphs. The significant value was set at $95 \%$ confidence level.

\section{RESULTS}

Hospital files of 848 patients were reviewed in this study. Of these number, $527(62.1 \%)$ were selected from the maternity ward and $321(37.9 \%)$ from the surgical ward. Of these, $668(78.8 \%)$ were females while $180(21.2 \%)$ were males. The sex ratio was 4 females to 1 male. Patients'ages ranged from 9 months to 78 years with a mean of 32.3 (32.3 $\pm 12.4)$. The majority of participants $(n=679)$ were aged between $21-50$ years, mostly females $(n=340)$ were in the 21 - 30 years age group. Most male participants $(21.1 \%)$ were aged $31-40$ years.

Concerning types of surgical procedures performed, the commonest of these in order of frequency were caesarian section, laparotomy, hernia repair, appendectomy, myomectomy, hysterectomy, ovarian cystectomy, splenectomy, prostatectomy and many others (Tables 1-4).

A total of 175 cases met the criteria for definition of postoperative infections giving a prevalence of $20.6 \%$. These consisted of purulent wound discharge from the surgical site (77.7\%), persistent body temperature $\geq 38.00 \mathrm{C}$ despite antimalaria treatment $(20.6 \%)$ or leucocytosis $(1.7 \%)$ on full blood count.

Concerning variation of postoperative outcome with patient's age, most cases of POIs (82.3\%) were in the 21-50 years age group. Meanwhile, the age group 0-10 years had the highest prevalence $(64.3 \%)$ of POIs. Sixty $(7.1 \%)$ of these patients were admitted and managed in the maternity ward.

Forvariation of postoperative outcome with gender, among the female postoperative cases $(n=668), 127(19.0 \%)$ developed POI. Meanwhile, of the 180 male participants, 48 
Table 2. Annual Variation of Prevalence of Surgical Procedures and Indications

\begin{tabular}{|c|c|c|c|c|}
\hline Procedure/ Indications & Year of $2009 n(\%)$ & Surgical $2010 n(\%)$ & Operation $2011 n(\%)$ & TOT. $n(\%)$ \\
\hline \multicolumn{5}{|l|}{ PROSTATECTOMY } \\
\hline -Benign prostatic hypertrophy & $2(40)$ & $1(20)$ & $1(20)$ & 5 \\
\hline -Prostate cancer & $1(20)$ & $0(0.0)$ & $0(0.0)$ & (100) \\
\hline \multicolumn{5}{|l|}{ APPENDICECTOMY } \\
\hline -A. appendicitis & $68(45.3)$ & $42(28)$ & $29(19.3)$ & \\
\hline -Appendicular mass & $5(3.3)$ & $0(0.0)$ & $1(0.7)$ & 150 \\
\hline -Chronic appendicitis & $1(0.7)$ & $0(0.0)$ & $0(0.0)$ & (100) \\
\hline -Gangrenous app. & $1(0.7)$ & $0(0.0)$ & $0(0.0)$ & \\
\hline -Appendicular abscess & $2(1.3)$ & $1(0.7)$ & $0(0.0)$ & \\
\hline \multicolumn{5}{|l|}{ MYOMECTOMY } \\
\hline -Symp. Ut. Fibroid & $6(20)$ & $17(56.7)$ & $7(23.3)$ & $\begin{array}{c}30 \\
(\mathbf{1 0 0})\end{array}$ \\
\hline \multicolumn{5}{|l|}{ OV.CYSTECTOMY } \\
\hline -Symp. LOC & $3(20)$ & $1(6.7)$ & $1(6.7)$ & \\
\hline -Symp. ROC & $2(13.3)$ & $3(20)$ & $0(0.0)$ & 15 \\
\hline -Symp. BOC & $4(26.7)$ & $0(0.0)$ & $1(6.7)$ & (100) \\
\hline HYSTERECTOMY & $1(4.8)$ & $0(0.0)$ & $0(0.0)$ & \\
\hline -Cervical ca & $0(0.0)$ & $1(4.8)$ & $0(0.0)$ & \\
\hline -Chorioamnionitis & $3(14.3)$ & $5(23.8)$ & $5(23.8)$ & \\
\hline -Symp. Ut. Fibroid & $2(9.5)$ & $1(4.8)$ & $2(9.5)$ & 21 \\
\hline -Placenta accrete & $1(4.8)$ & $0(0.0)$ & $0(0.0)$ & $(\mathbf{1 0 0})$ \\
\hline Uterine atonia & & & & \\
\hline
\end{tabular}

Table 3. Annual Variation of Prevalence of Surgical Procedures and Indications

\begin{tabular}{|c|c|c|c|c|}
\hline Procedure / Indications & Year of $2009 n(\%)$ & Surgical $2010 n(\%)$ & Operation $2011 n(\%)$ & Total $n(\%)$ \\
\hline \multicolumn{5}{|l|}{ CAESAREAN SECTION } \\
\hline -Multiple gestation & $3(1.0)$ & $10(3.4)$ & $13(4.4)$ & \\
\hline -Abruptio placentae & $1(0.3)$ & $3(1.0)$ & $5(1.7)$ & \\
\hline -Acute foetal distress & $22(7.5)$ & $20(6.8)$ & $11(3.7)$ & \\
\hline -Cephalopelvic disproport & $20(6.8)$ & $16(5.4)$ & $10(3.4)$ & \\
\hline -Antepartum haemorrhage & $1(0.3)$ & $3(1.0)$ & $2(0.7)$ & \\
\hline -Breech in primi & $9(3.1)$ & $11(3.7)$ & $4(1.4)$ & \\
\hline -Cervical dystocia & $5(1.7)$ & $4(1.4)$ & $6(2.0)$ & \\
\hline -Cord prolapsed & $2(0.7)$ & $2(0.7)$ & $3(1.0)$ & \\
\hline -Double scar & $7(2.4)$ & $8(2.7)$ & $3(1.0)$ & 295 \\
\hline -Hypertension disorders & $7(2.4)$ & $12(4.1)$ & $7(2.4)$ & $(\mathbf{1 0 0})$ \\
\hline -Convinience & $1(0.3)$ & $2(0.7)$ & $3(1.0)$ & \\
\hline -Failure of induction & $8(2.7)$ & $10(3.4)$ & $9(3.1)$ & \\
\hline -Placenta praevia IIIB & $9(3.1)$ & $6(2.0)$ & $0(0.0)$ & \\
\hline -Malposition & $2(0.7)$ & $6(2.0)$ & $7(2.4)$ & \\
\hline -Neglected shoulder & $3(1.0)$ & $5(1.7)$ & $2(0.7)$ & \\
\hline -Obstructed labour & $7(2.4)$ & $2(0.7)$ & $5(1.7)$ & \\
\hline -Post date & $3(1.0)$ & $3(1.0)$ & $1(0.3)$ & \\
\hline
\end{tabular}


Table 3. contd...

\begin{tabular}{|c|c|c|c|c|}
\hline Procedure / Indications & Year of $2009 n(\%)$ & Surgical $2010 n(\%)$ & Operation $2011 n$ (\%) & Total $n(\%)$ \\
\hline -Transverse lie & $5(1.7)$ & $4(1.4)$ & $5(1.7)$ & \\
\hline - Uterine rupture & $4(1.4)$ & $2(0.7)$ & $1(0.3)$ & \\
\hline -PROM & $4(1.4)$ & $5(1.7)$ & $5(1.7)$ & \\
\hline
\end{tabular}

Table 4. Annual Variation of Prevalence of Surgical Procedures and Indications

\begin{tabular}{|c|c|c|c|c|}
\hline Procedure / Indications & Year of $2009 n(\%)$ & Surgical $2010 n(\%)$ & Operation $2011 n(\%)$ & Total $n(\%)$ \\
\hline \multicolumn{5}{|l|}{ TUBAL LIGATION } \\
\hline -Self request & $0(0.0)$ & $1(33.3)$ & $1(33.3)$ & 3 \\
\hline -R. Tubal pregnancy & $0(0.0)$ & $1(33.3)$ & $0(0.0)$ & (100) \\
\hline \multicolumn{5}{|l|}{ SPLENECTOMY } \\
\hline \multicolumn{5}{|l|}{ OTHERS } \\
\hline \multicolumn{5}{|l|}{-Orchidopexy } \\
\hline -Nodulectomy & $5(50)$ & $2(20)$ & $3(30)$ & 10 \\
\hline \multicolumn{5}{|l|}{$\begin{array}{l}\text {-Omphalocele repair } \\
\text {-Hydrocele repair etc }\end{array}$} \\
\hline
\end{tabular}

Symp. LOC: Symptomatic Left Ovarian Cyst, ROC: Right Ovarian Cyst, BOC: Bilateral Ovarian Cyst, Ca: Cancer, Symp. Ut. Fibroid: Symptomatic Uterine fibroid, PROM: Premature Rupture of Membranes

\section{Variation of POI with age and gender}

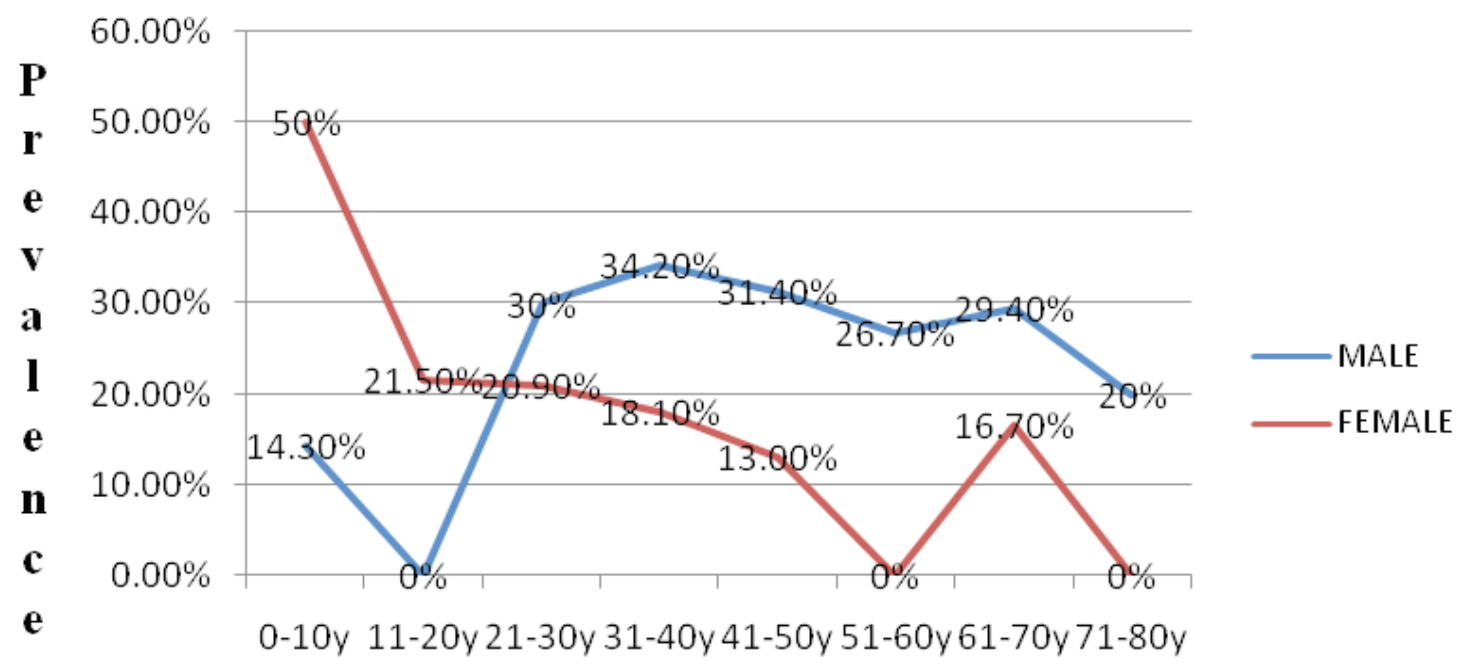

\section{Participants' age group}

Fig. (1). Variation of POI with age and gender.

(26.7\%) had POI. The relationship between POI and the sex of the participant was statistically significant $(\mathrm{p}<0.05)$. Females (77.1\%) were more infected among the 144 infected cases in the age group $21-50$ years. Besides, all the participants $(n=4)$ who died after surgery from noninfectious causes were females (Fig. 1).

Postoperative outcome per hospitalization ward was variable. Of the 175 cases who developed POIs, 109 (62.3\%) 


\section{Prevalence of diagnostic criteria for POI per unit of hospitalisation}

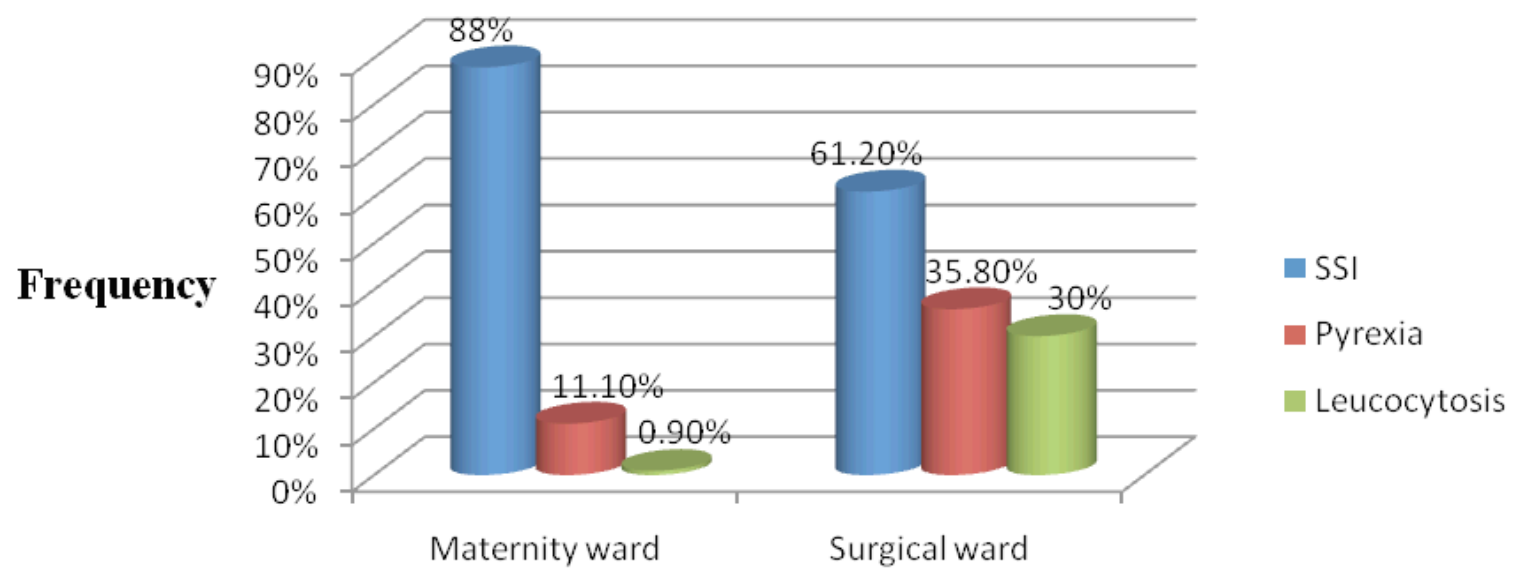

Unit of hospitalisation

Fig. (2). Diagnostic criteria for POIs.

\section{Annual variation of postoperative outcome}

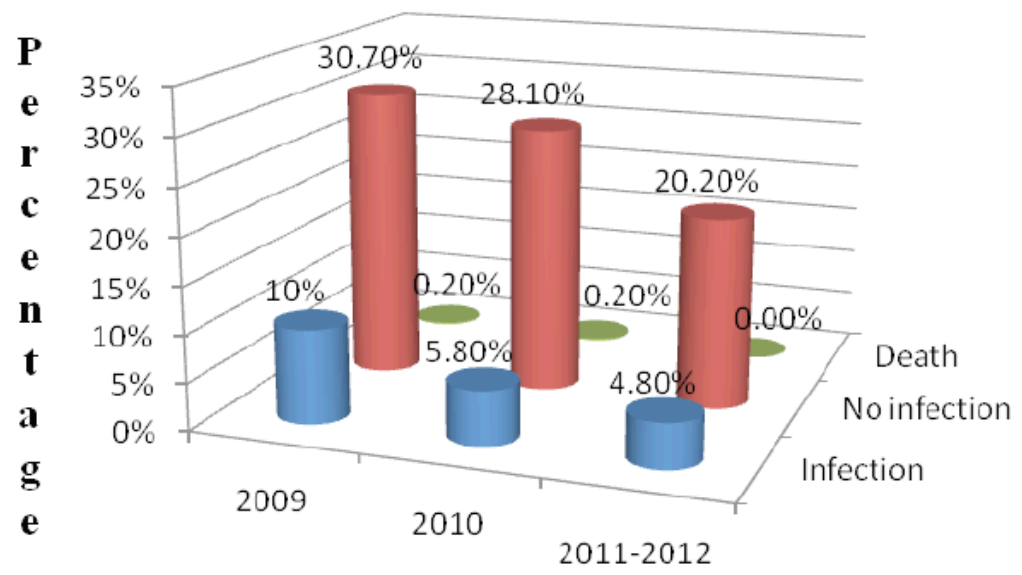

Infection

No infection

Death

Year

$$
\mathrm{X}^{2}=7.167, \mathrm{P}=0.127
$$

Fig (3). Annual variation of POIs.

were from the maternity ward while $66(37.7 \%)$ were from the surgical ward. There was, however, no statistical significant difference in the rate of postoperative infection and the hospitalization ward $(\mathrm{P}>0.05)$. However, of the 527 maternity cases, $20.7 \%$ developed POI meanwhile $20.6 \%$ of the 321 cases from the surgical ward had POI. It was noted that $4(0.5 \%)$ participants who died from non-infectious causes after surgery were all from the maternity.

The prevalence of POI diagnostic criteria was also variable. The majority of the infected cases were reported to present with purulent discharges from the surgical sites [136 $(77.7 \%)]$ in both the maternity $(61.2 \%)$ and the surgical wards $(88.0 \%)$ (Fig 2). There was astatistical significant difference between diagnostic criteria and rate of POIs $(\mathrm{P}<$ 0.05). Annual variation of POI was also observed (Fig. 3). It was also realized that the rate of postoperative infections among the subjects reduced consecutively from 2009 to 2012. However, statistically there was no significant difference between postoperative outcome and the year of study $(\mathrm{P}>0.05)$. The infection rate was also linked to the surgical procedures used.

Most of the patients who were selected from the maternity ward underwent a Caesarean section $(56 \%)$. In the surgical ward, $152(47.4 \%)$ of the hospitalized patients had undergone a hernia repair; the prevalence of POI was variable as regarding surgical procedure.Out of the 295 patients who underwent a Caesarean operation, 77 (26.1\%) developed a postoperative infection. Of the 152 participants who had a hernia repair through surgery, $10(6.5 \%)$ had an infection after surgery. Meanwhile $10(6.7 \%)$ out of the 150 
Table 5. Rate of POI Per Surgical Procedure

\begin{tabular}{|c|c|c|c|}
\hline Procedure & Indications & Infected $n$ & Total $n \%$ \\
\hline Laparo & $\begin{array}{l}\text { Peritonitis } \\
\text { Bowel perf. } \\
\text { Bowel obst. } \\
\text { Pelvic absc. } \\
\text { Ruptured EP } \\
\text { Others }\end{array}$ & $\begin{array}{l}15 \\
6 \\
6 \\
3 \\
5 \\
6\end{array}$ & $41(26.1)$ \\
\hline Hernia repair & $\begin{array}{l}\text { LIH } \\
\text { RIH } \\
\text { BIH } \\
\text { FH } \\
\text { UH } \\
\text { EP }\end{array}$ & $\begin{array}{l}3 \\
2 \\
2 \\
0 \\
2 \\
1\end{array}$ & $10(6.6)$ \\
\hline Prostatectomy & $\mathrm{BPH}$ & 7 & $7(35)$ \\
\hline Appendicectomy & Acute app. & 10 & $10(6.7)$ \\
\hline Myomectomy & Symp. Ut. Fib. & 2 & $2(3.6)$ \\
\hline Cystectomy & Symp. Ov. Cyst & 10 & $10(25)$ \\
\hline $\mathrm{C} / \mathrm{S}$ & Varied & 77 & $77(26.1)$ \\
\hline Hysterectomy & $\begin{array}{l}\text { Symp. Ut fib. } \\
\text { Cerv/ut. ca }\end{array}$ & $\begin{array}{l}2 \\
5\end{array}$ & $7(20)$ \\
\hline Tubal ligation & Contraception & 0 & 0 \\
\hline Splenectomy & $\begin{array}{l}\text { Splenic rup. } \\
\text { Tropical spleen }\end{array}$ & $\begin{array}{l}4 \\
1\end{array}$ & $5(31.2)$ \\
\hline Others & Varied & 6 & $6(15.4)$ \\
\hline Total & & & $175(20.6)$ \\
\hline
\end{tabular}

appendicectomy cases reviewed from the surgical ward developed an infection after surgery. A total of 157 patients had a laparotomy and of this number, 41 (26.1\%) developed POI. Majority of the laparotomies $(36.6 \%)$ that ended with POI were indicated for peritonitis (Table 5). The least infective of the procedures were tubal ligation and myomectomies which had infection rates of $0 \%$ and $3.7 \%$, respectively. Mean postoperative stay among patients with SSIs and those without SSIs was 15.5 days and 10.2 days, respectively.

\section{DISCUSSION}

In this study, females (78.8\%) were more represented than men with a sex ratio in their favour of 4: 1 . Mahmoud [2] also described a majority of women in his study in Pennsylvania (USA) with $53 \%$ in 2009 . This was contrary to the proportion found by Taye [3] in Ethiopia with $66.2 \%$ of men in his study in 2005.

Infections after surgery have significant effects in the postoperative morbidity and mortality of patients, especially in the tropics [4]. The prevalence of infection after surgery studied from January 2009 to August 2012 was estimated to range from $0-36.6 \%$ with a mean of $20.6 \%$. The decreased rate of POIs from 2009 to 2012 could be due to a better use and distribution of antibiotics. This range was similar to the rates of $2.5-30.9 \%$ estimated in Nigeria [5]. In addition, our results agree with the $5.7-48.8 \%$ prevalence estimated in Nigeria in 2004 [6]. However, the mean rate of POI in our study was relatively higher than the $11.9 \%$ prevalence obtained in Algeria in 2006 [7]. The prevalence range of POIs in this study also agrees with estimates in the USA (Salt Lake City) which had a SSI rate of 9.1\% [8]. The relatively higher mean of POI $(20.6 \%)$ can probably be explained by the fact that most of our participants were postcaesarean section patients. The surgical site after a Caesarean section $(\mathrm{C} / \mathrm{S})$ is more prone to infection given that there is a direct connection between the site and the bacteria flora environment of the vagina. Besides, before a $\mathrm{C} / \mathrm{S}$, the patient is subjected to multiple vagina/cervical examinations which carry bacteria from the vagina into the bacteria-free uterine cavity. The rate of $19.4 \%$ of SSIs after Caesarean section was similar to $7-20 \%$ reported by Sullivan et al. [9] in 2007 , 
and an overall $19 \%$ prevalence registered in Kenya [10]. Moreover, laparotomy for acute generalized peritonitis (AGP) is a contaminated procedure with an already infected (bacteria) environment which exposes the surgical sites to SSIs. In this study, purulent discharge from the operation site (SSI) was diagnostic of POI in majority of the cases identified ( $\mathrm{n}=136)$. Maternity ward accounted for $88 \%$ of the SSIs. This result was higher than the value obtained from a study carried out on 770 obstetric cases in Jimma University Specialized Hospital in Ethiopia with 11.4\% [11]. The discrepancy in the results could be due to the fact that the Ethiopian study was prospective. Besides, postoperative pyrexia was identified in 36 cases $(20.6 \%)$ with POI. This value was slightly higher than the $13.7 \%$ estimated from a study conducted in Mulago Hospital in Uganda [12]. However, the latter was a prospective study. Overall, our results had a similar pattern to the diagnostic criteria of POI in Uganda [10], but contrary to what was obtained in South Africa [13] where postoperative pyrexia was predominant $(41.0 \%)$. This result can be explained by the routine surgical site examination during the postoperative follow- up by the surgeon.

Furthermore, more male participants developed POIs (26.7\%) than their female counterparts. It was also found that the gender of the participants was significantly related $(\mathrm{p}=0.009)$ to the postoperative infectious outcome. The Male: Female ratio in our study was 1:4; meanwhile the sex ratio of participants who developed POIs was 1:3. This finding was contrary to that obtained from a retrospective study carried out in South Africa which had a male to female ratio of 3.6:1 [13]. However, the latter study reviewed only appendectomy cases without including obstetric operations. Although a majority of our participants were females, males relatively developed infections after surgery (48 out of 180) compared to females (127 out of 668). We had no clear explanation for this finding. It was realized that of the 175 cases that developed infection following surgery, 108 $(12.7 \%)$ were patients admitted into the maternity wards. The relationship between POI and the sex of the participant was statistically significant $(\mathrm{p}<0.05)$. Females $(77.1 \%)$ were most infected among the 144 infected cases in the age group $21-$ 50 years.

Furthermore, hernia repairs that developed POIs after surgery were $10(6.5 \%)$ in our study. This result was similar to the $3.5-4.9 \%$ obtained in a systematic review done among patients who had undergone a hernia repair [14]. It was found that out of the 41 laparotomy that developed POI, $36.6 \%$ were indicated for acute generalized peritonitis (contaminated surgery). This finding was similar to results obtained from a study conducted in Nigeria which showed that contaminated wounds had infection rates of $13.3-$ $51.9 \%$ after a surgical operation [5]. The same study revealed that clean wounds had an infection rate of $6.5-$ $20.2 \%$ following a surgical intervention. The latter is in agreement with the results of our study which showed the infection rate among clean wounds, like those after a hernia repair, were $6.5 \%$.The septicity of the aetiology was one of the factors explaining the rate of infection rate. Aseptic operations had less infection rate as for tubal ligation whereas peritonitis had the highest rate. Besides, this study found the mean postoperative hospital stay among patients with SSIs to be 15.5 days. This result was similar to, but lower than, the 19.6 days estimated in an Ethiopian study [12]. From this study, the overall postoperative mortality rate was found to be $0.5 \%$. This was lower than the $4.9 \%$ recorded from a study done in Ethiopia [12]. The mortality rate from surgery in developing countries was estimated to be $5-10 \%$ [15]. The low mortality rates in this study could be explained by the utilization of broad-spectrum antibiotics following a surgical intervention which go a long way to controlling POIs.

\section{CONCLUSION}

The prevalence of postoperative infections in the Limbe Regional Hospital over a 43-month period (2009-2012) ranged between $0-36.6 \%$, with a mean of $20.6 \%$. The age group $0-10$ years had the highest rate of POIs. The male sex seemed to be significantly related to the rate of POIs. Age of participants also had a significant risk to POIs. Laparotomies for acute generalized peritonitis developed most of the infections after surgery. Therefore, contaminated procedures carry a higher risk of POIs than clean surgical procedures. The hospitalization ward did not pose any significant risk to the development of POIs; rather the duration of hospitalization was a risk factor for the development of POIs.

\section{CONFLICT OF INTEREST}

The authors confirm that this article content has no conflicts of interest.

\section{ACKNOWLEDGEMENTS}

Declared none.

\section{REFERENCES}

[1] Ouro-Bang'naMaman AF, Agbetra N, Moumouni I, Tomta K, Chobli M. management of postoperative pain in togo: knowledge and attitude of prescribers. J Afr Chir Digest 2006; 53(5): 529-31.

[2] Mahmoud NN, Turpin RS, Yang G, Saunders WB. Impact of surgical site infections on length of stay and costs in selected colorectal procedures. Surg Infect (Larchmt) 2009; 10(6): 539-44.

[3] Taye M. Wound infection in Tikur Anbessa hospital, surgical department. Ethiop Med J 2005; 43(3): 167-74.

[4] McConkey SJ. Case series of acute abdominal surgery in Rural Sierra Leone.World J Surg 2002; 28: 509-13.

[5] Ameh EA, Mshelbwala PM, Nasir AA, et al. Surgical site infection in children: prospective analysis of the burden and risk factors in a sub-Saharan African setting. Surg Infect (Larchmt) 2009; 10(2): 105-9.

[6] Kesah CN, Egri-Okwaji MT, Iroha E, Odugbemi TO. Aerobic bacterial nosocomial infections in paediatric surgical patients at a tertiary health institution in Lagos, Nigeria.Niger Postgrad Med J 2004; 11(1): 4-9.

[7] Atif ML, Bezzaoucha A, Mesbah S, Djellato S, Boubechou N Bellouni R. Evolution of nosocomial infection prevalence in an Algerian University Teaching Hospital (2001 to 2005). Med Mal Infect 2006; 36(8): 423-8.

[8] Lazarus HM, Fox J, Burke JP, et al. Trauma patient hospitalassociated infections: risks and outcomes. J Trauma 2005 ; 59(1): 88-94.

[9] Sullivan SA, Smith T, Chang E, et al. Wilson. Administration of Cefazolin prior to skin incision is superior to Cefazolin at cord clamping in preventing post caesarean infectious morbidity: a randomized, controlled trial. Am J Obstet Gynecol 2007; 196: 455.

[10] Koigi-Kamau R, Kabare LW, Wanyoike-Gichuhi J. Incidence of wound infection after caesarean delivery in a district hospital in central Kenya. East Afr Med J 2005; 82(7): 357-61. 
[11] Amenu D, Belachew T, Araya F. Surgical site infection rate and risk factors among Obstetric cases of Jimma University Specialised Hospital, South West Ethiopia. Ethiop J Health Sci 2011; 21(2): 91-100.

[12] Ntakiyiruta G, Mugisa BD, Watya SG. Early Outcome of Postoperative Pyrexia Following Major Surgery in Mulago Hospital. East Central Afr J Surg 2006; 11(2): 12-6.
[13] Chamisa I. Clinicopathological Review of 324 appendices removed for Acute Appendicitis in Durban, South Africa: A Retrospective Study. Ann R Coll Surg Engl 2009; 91(8): 688-92.

[14] Sanchez-Manuel EJ, Lozano-Garcia J, Seco-Gil JL. Antibiotic prophylaxis for hernia repair. Cochrane Database Syst Rev; 2012; no. 2 .

[15] Bickler SW, Sanno-Duanda B. Epidemiology of Paediatric Surgical Admissions to a Government Referral Hospital in Gambia. Bull World Health Organ 2000; 78: 1330-6.

(C) Ngowe et al.; Licensee Bentham Open.

This is an open access article licensed under the terms of the Creative Commons Attribution Non-Commercial License (http://creativecommons.org/licenses/by$\mathrm{nc} / 3.0 /$ ), which permits unrestricted, non-commercial use, distribution and reproduction in any medium, provided the work is properly cited. 